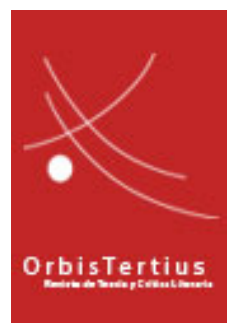

Orbis Tertius, vol. XXII, n 25, e049, junio 2017. ISSN 1851-7811

Universidad Nacional de La Plata

Facultad de Humanidades y Ciencias de la Educación

Centro de Estudios de Teoría y Crítica Literaria

\title{
Gustavo Lespada, Carencia y literatura. El procedimiento narrativo de Felisberto Hernández.
}

\author{
Buenos Aires, Biblios, 2016, 210 páginas.
}

\section{Enrique Foffani}

Bajo un epígrafe, por muchos motivos paradigmático, del poeta francés Edmond Jabès ("Es lo que no se ve lo que nos permite ver" (porque) "La clave es, sin duda, la carencia”), el libro de Gustavo Lespada, que recibió el Premio a las Letras 2016 en la categoría de ensayo literario, inscribe de entrada a Felisberto Hernández en la relación siempre problemática entre, por un lado, los procesos de creación artística (en tensión con la constitución de la figura del intelectual) y, por otro lado, los medios precarios, escasos o nulos del entorno tal como ha sido en América Latina casi la norma. Esto se refiere a la escasez de medios materiales como la situación corriente de los artistas latinoamericanos que no provenían ni de la elite que acaparaba recursos económicos y capitales simbólicos ni de las familias acomodadas en ese pasaje entre una mentalidad hidalga a la mentalidad burguesa sino de aquellas familias de incipiente clase media que habían podido acceder por medio del trabajo (o la universidad) desde fines del siglo XIX y comienzos del XX, a los bienes culturales gracias al proceso (aunque desigual) de las democracias en el continente. M'hijo el dotor como bien lo describió el uruguayo Florencio Sánchez. Otro oriental, Ángel Rama, lo sabemos, describió los avatares desde la colonia de ese cogollo urbano que denominó la ciudad letrada para referirse a ese espacio cerrado, compacto, de todos los que habían accedido a los signos y a la letra, (la escritura), mientras que por fuera de las murallas de la ciudad se extendía la otra ciudad que tensaba —en esa puja por el dominio del poder - las voces anónimas y populares que constituían la ciudad periférica, la “ciudad oral”, una ciudad 
más vital que la otra y más atenta a la escucha del otro. Reúno la tesis de Ángel Rama con el epígrafe de Edmond Jabès porque es, en esta encrucijada entre una mirada local de nuestra historia latinoamericana y una mirada universal sobre lo que entendemos es el patrimonio cultural, que se juega toda la propuesta crítica de Lespada: su libro - tesis doctoral defendida en la Universidad de Buenos Aires— está escrito en el medio de la disyuntiva latinoamericana por antonomasia, entre las dos aguas que implica no desasirse de la historia de nuestra cultura americana y al mismo tiempo no dejar de acceder, casi como un derecho propio, a la cultura universal, en la estela de lo planteado por Borges acerca de que "debemos pensar que nuestro patrimonio es el universo". Se trata de un derecho para todo americano que lo obliga a la mirada dual. Encrucijada es eso: cruce de caminos, disyuntivas entre el saber y la experiencia, dilemas entre el adentro y el afuera, alternativas que exigen, de todos modos, tomar posición desde la periferia —o desde "la periferia de la periferia”, como plantea otro crítico uruguayo Hugo Achugar- acerca de lo que podemos llamar sin ambages la cuestión de las apropiaciones culturales que está en el corazón de la formación de toda cultura como fermento de otredad, de alteridades, de identidades constitutivamente heterogéneas, es decir, la cultura atravesada por funciones esencialmente transitivas que la vuelve, en ese contacto o interacción vital, transcultura. Todo proceso cultural deviene transcultural: por la lengua, por la religión, por la sociedad, por la política, por las creencias, por las concepciones del mundo, por innúmeros factores que operan descentrando y situándose de modo ex-céntrico en los márgenes o sus bordes.

El libro de Lespada sobre Felisberto trabaja a dos puntas, se mueve a dos aguas, ejerce una rotunda ubicuidad crítica que le permite desarrollar un abordaje formalista, mediante un buceo retórico casi sin precedentes en la crítica latinoamericana y terminar, pese a ello, siendo un libro sobre sociología de la literatura latinoamericana. Rara, o al menos extraña manera de ser dual en el saber crítico: por un lado, una retórica minuciosa, meticulosamente detallista que despliega sus tentáculos casi infinitos sobre el texto felisbertiano - uno tiene la sensación, que es más que una sensación, de que un estudio sobre figuras y tropos se parece a un abismo- - y que, precisamente por ello, se ahonda en la dimensión lingüística de la narrativa y por el otro, una interpretación sociológica de la figura del artista, del escritor, en este caso de un narrador como Felisberto que, como bien sabemos, reunía en su figura las marcas de la exclusión, de la marginalidad, del out-sider, del autodidacta y tantos otros perfiles que fueron componiendo la imagen de un escritor tan raro como conocido en su rareza multisignificativa, ya que Felisberto fue raro por muchas razones y cuando, con el correr del tiempo, decaían alguna de ellas, se tornaba menos raro en un aspecto pero aumentaba en otros, una suerte de círculo vicioso de las domesticaciones que no consiente bajo ningún punto de vista la cancelación de las etiquetas.

Quisiera detenerme en los fundamentos ubicuos que este libro sobre Felisberto expone de un modo sutil pero contundente, es decir, se trata de una crítica que requiere de una atención muy fina por parte del lector a la hora de sopesar el modo de leer y, sobre todo, del modo de leer a un autor como Felisberto cuya excentricidad curiosamente impedía ver su lado invisible, el lado B que no mostraba (que no mostraba en la lógica de la carta robada de Poe, esto es, en la lógica de mostrarse oculta a la vista de todos). Por eso el epígrafe de Edmond Jabès es crucial cuando afirma que la clave de la carencia reside en que ella misma nos proporciona su contrario, a saber: es el no tener lo que nos deja ver el tener, de allí que la metáfora de la visión habilita la paradoja de que sea lo que no se ve lo que permite ver. Y siguiendo a Edmond Jabès, la pregunta consiste en qué es lo que no se dejaba ver todavía de Felisberto, qué clave de carencia es posible esgrimir, desde la crítica, para determinar de algún modo aquello que, aun entre las sombras, había que traer a la luz. Visión y ceguera —un título del crítico norteamericano Paul de Man- son los términos de un comportamiento paradojal: la crítica enceguecida no puede ver pero la visión puede nacer - y de hecho así ocurre- de la ceguera, como Edipo que cuando veía, no sabía y cuando pierde la vista se vuelve el ciego que sabe: todo el libro de Lespada somete el texto felisbertiano al análisis retórico minucioso como una 
manera de ahondar en las diversas capas del sentido para contrarrestar la ceguera de la crítica y devolverle la vista al lector o mejor: devolver el texto [felisbertiano] a la visión, menos porque se trate de un narrador visionario que porque hace de la imaginación una visión particular (Lespada prefiere y propone otro atributo: "singular", de allí que el libro sea una suerte de explicación formal de la tan mentada singularidad del uruguayo) y, contra todos los rótulos impuestos, Lespada rechaza de entrada la posibilidad de considerarlo un autor de literatura fantástica. En otras razones de peso, porque esa "fuerza de la imaginación” de Felisberto lo retiene en el mundo real en que vivimos.

Eso es, precisamente, lo que lo asemeja, sólo en este aspecto, a Onetti: nunca viran hacia el fantástico, más bien se trata de un fantasmático. Los une ese flujo incesante de la actividad fantasmática del sueño diurno, de infinitos mundos posibles que albergan dentro del único mundo real que habitamos. Aun cuando no podamos ignorar las lecturas sobre el fantástico que los textos felisbertianos han suscitado en el discurso crítico latinoamericano, la negativa por parte de Lespada por sacarlo de ese sitio, responde precisamente al hecho de que la tremenda fuerza imaginativa se juega también, sobre todo, en el plano de la lengua allí donde las transacciones incesantes entre el significante y los infinitos significados demuelen cualquier anclaje del sentido o mejor: lo disparan hacia regiones impensadas, al abrigo de la cristalización semántica.

Como hemos ya planteado, Lespada no apela a Paul de Man sino a un poeta, a Edmond Jabès, para explicar las múltiples operaciones del sentido que dispara la lengua narrativa de Felisberto. El poeta francés plantea que la carencia sustancial radica en las palabras, separadas desde siempre de las cosas, y la carencia sería la clave porque es ella misma como ausencia la que suscita la presencia del lenguaje. Para decirlo de una vez y declarar de entrada la tesis de Lespada: lejos de anularlo como Artista (como Narrador), la carencia le permite hacer una obra; lejos de aminorar o anular las fuerzas de la creatividad que todo Artista tiene (el don, el talento) y al mismo tiempo adquiere (la técnica), la carencia se disemina en una serie de aspectos, de instancias, que van desde las más materiales a las más espirituales, esto es, desde los libros sin tapas —ésta es una de las imágenes más radicales de la carencia: que un libro que se precie de tal carezca de tapas- a la desposesión del saber hay un universo de significaciones de la falta que Lespada declara como uno de los núcleos constitutivos de la narrativa felisbertiana. En este libro, encontraremos la formulación de una teoría crítica de la carencia en el ámbito de la literatura latinoamericana cuyas valencias son numerosas y sin ánimo de agotar los matices que se sutilizan a lo largo del libro, entre las de mayor relevancia señalamos la carencia económica (carencia de recursos); la carencia como el no-saber; la carencia como atributo de la figura del narrador; la carencia de propiedad o de "materias primas" que congrúe en parte con la esfera de la economía ya señalada pero apuntala otros aspectos que atañen a los bienes culturales y los capitales simbólicos; todo lo cual define una teoría de las faltas que se ajusta no sólo al entorno del artista (narrador) sino que parece ser una instancia que consigue solaparse, intrometerse en las múltiples instancias materiales y espirituales de la obra de Felisberto.

Esta teoría de la carencia es sometida a la vez a la dualidad de la que habláramos al principio: por un lado Lespada persigue este núcleo en las napas lingüístico-semióticas de la retórica y, en esta línea, habría que pensar que el rol protagónico que se le confiere en este estudio a la "metonimia” [figura que definimos, en principio pero exclusivamente, como la parte por el todo] implica precisamente uno de los comportamientos de la carencia: ser tan sólo "una parte" del todo, una "porción” de la totalidad, una "parcela” la mayoría de las veces escasa e insuficiente para enfrentar la completud - lo que equivale a decir que in nuce la metonimia es "la clave de la carencia" en el sentido de que, aun cuando se halle a expensas de la restricción y la reducción, se trata de un recurso que busca aventajar y superar el déficit de lo particular para alcanzar el superávit del sentido. ¿No es acaso lo que Lespada parece haber pretendido con su tesis, esto es, hacer del texto felisbertiano la posibilidad de no verlo ya reducido a una parte sino expandirlo a una esfera mayor y desde allí pergeñar otra imagen de escritor? ¿No es acaso la lógica paradojal de la carencia con su clave de 
hacer hablar desde el no tener, lo mismo que planteaba desde un régimen escópico [visivo/visual] Edmond Jabès de hacer ver lo que no se ve? Y más todavía: ¿№ es esta lógica paradojal la que puesta a actuar en el análisis de los textos que Lespada despliega la que combina el régimen escópico con el gnoseológico y la carencia entonces se transforma en un motor que hace funcionar todo el engranaje del texto felisbertiano? $\dot{¿} Y$ desde la perspectiva la carencia no se juega como el signo ineludible de la tensión entre saber y no-saber o si se quiere no es, por tanto, eso tan asiduo en los relatos de Felisberto que es el saber que proviene de un lado de la experiencia y por el otro el conocimiento que no tiene y porque no lo tiene lo inventa? Sobre estas disyuntivas tiene que trabajar el libro de Lespada si quiere poner a Felisberto en otro lugar, esto es, no ponerlo en un lugar apropiado, como si hubiera el lugar que le corresponde ocupar en el contexto de la literatura uruguaya —no hay tales sitios en el interior de la crítica - sino más bien cambiarlo de lugar y en esa dislocación verlo de otro modo o para seguir con el régimen de la paradoja lo que no se ve, lo que no se tiene puede ser la matriz que nos haga pensar el modo como en los relatos de Felisberto aparece el saber o se inventa o se narra para no sabiendo precisamente saber, todas variaciones que constituyen los fundamentos de su narración. Basta tomar el incipit (el comienzo del relato En los tiempos de Clemente Colling) para condensar tales variantes en el arte de narrar felisbertiano. No es solamente la tensión saber vs no-saber sino también saber poco o no saber bien, cuyas combinaciones pueden otorgarnos una serie innumerable de posibilidades: saber no es, en el fondo, saber lo que se sabe (la consabida doxa, el lugar común) pero no saber tampoco implica la negatividad absoluta ya que, como una forma de la carencia, genera la escritura. Hay una recursividad hermenéutica en Felisberto que nos hace sospechar un trasfondo filosófico sobre las indagaciones del lenguaje, sobre todo si pensamos en Wittgenstein o Russell como aquellos pensadores modernos que mostraron el vacío del lenguaje como contrapartida de la ineficiencia del conocimiento, como aquellos que instalaron la modernidad en la puesta en crisis y en situación-de-fracaso del lenguaje que quizá no pueda decir sin más lo que pretende decir y dice entonces, tal vez, otra cosa: Felisberto hace de este tipo de argumentaciones provenientes de la filosofía del lenguaje — no importa si los haya leído o conocido de primera o segunda mano, porque en los años veinte ya flotaban en el aire estas ideas, lo que los alemanes denominan "Zeitgeist”, esto es, el espíritu de la época arraigado a un determinado momento histórico — una forma del relato en el cual lo que aparece es, precisamente, lo que Lespada denomina lo no-dicho y es, sin duda alguna, esa otra cosa que se le escapa siempre al lenguaje, que se le pierde, esa otra cosa que se dice a pesar de todo, esa otra cosa pujante desde las más remotas profundidades (si pensamos en Freud a partir del lapsus, los sueños, el inconciente), esa otra cosa que puede ser también la manifestación de lo perverso como índole insoslayable de lo humano. Lespada persigue la lógica de lo paradojal (que lo que no se sabe se sepa; que lo que no se ve, que se vea; que lo que no se tiene, que aparezca) en muchos planos y el modo de abordar los trastrocamientos lo hace a partir de todas las operaciones de la lengua que el radar de la retórica parece detectar en una serie de figuras y de tropos (metonimia, prosopopeya, catacresis, zeugmas) desde las regiones más microscópicas de la frase.

Como indica en los dos títulos del libro: de un lado, la retórica de la carencia que se vuelve motor de la escritura (exhibir el no-saber, lo que sé, lo que una época no puede decir ni pensar, eso tal vez lo puedan anticipar los artistas) y del otro, los procedimientos narrativos que reponen el vacío, es decir, de algún modo lo llenan. Ambos enunciados se complementan o mejor será decir se suplementan, sin embargo en lo que concierne al procedimiento la significación se bifurca: lo que pertenece al arte de narrar y lo que pertenece al orden de los comportamientos, esto es, el modo como proceden las formas, como se comportan cuando la trama ya no es la literaria o meramente narrativa sino social y política. La inubicación de los textos de Felisberto muchas veces se debió no tanto a la rareza como al modo de proceder lingüísticamente, insolentes en su gestos e impertinentes en la medida en que se comportan a contrapelo de las buenas costumbres. Textos, los de Felisberto, díscolos respecto de los buenos modales, todo lo cual lo acerca en los años veinte a los comportamientos textuales de la poesía de César Vallejo, ambos con ese aire vanguardista de dinamitar 
todos los niveles del lenguaje desde el semántico al sintáctico. Ambos se sitúan en un lugar incómodo, sobre todo inestable, como si nada pudiera en el fondo domesticar el Sentido.

Quisiera condensar en tres líneas de sentido la propuesta central del libro como un modo, no de cerrar, sino, por el contrario, de abrir las reflexiones que suscita en el marco de la crítica latinoamericana.

1) Lespada enfrenta críticamente el conjunto de nociones que constituían la imagen de Felisberto, a saber: originalidad; rareza/extrañeza; excentricidad; singularidad. Ante ellas, va oponiendo diversos argumentos y mostrando que, con el correr del tiempo, se volvían ineficaces. Vaciadas de contenido, ninguna de esas nociones sobreviven a los nuevos paradigmas de la crítica: al mito romántico de la originalidad, Lespada opone singularidad y argumenta que ésta quizás resida en todo "aquello que no pudo ser dicho", una suerte de potencialidad del sentido en estado de sedimentación. En correlato con el método formal que propone desde el principio, la singularidad encarna el fantasma de la especificidad que no es, en el análisis de Lespada, una sustancia sino una modalidad, no una esencia sino un modo, un recurso, un atributo. Bien aprendida la lección de los formalistas rusos, vecinos y cómplices en más de un sentido de los artistas de vanguardia, el estudio de Lespada acerca de la narrativa de Felisberto hace de la singularidad un constructo retórico entre el plano del significante y la trama secreta del inconsciente de la lengua. De allí que acerque la lengua felisbertiana a los mecanismos (procedimientos, estrategias, operaciones, recursos) propios del lenguaje poético. Por eso de la segunda noción la rareza o extrañeza, lo que más importa ahora no es tanto si Felisberto fue o no el Raro sino los efectos de extrañamiento que el uso de su lenguaje suscitó en la prosa narrativa. Ahora bien, con respecto a la noción de excentricidad también Lespada parece propinarle su buena estocada: puesta en relieve la trama tupida de la lengua plagada de tropismos y figuraciones, lo que importa ahora son las salidas o las fugas del centro entendidas como dislocaciones que conectan decisiones estéticas y entorno socio-histórico; de hecho Lespada descoloca a Felisberto de todos los ismos. Lo hace desertar tanto del Realismo como del Fantástico, tanto de la literatura Autobiográfica como de la literatura Hiperrealista. Quizás el lugar más asequible sea el de las vanguardias históricas pero despeja, sin embargo, una inscripción demasiado ortodoxa al surrealismo. Para Lespada la singularidad de un narrador es una construcción y nunca una etiqueta. Felisberto es vanguardista bastante parecido a como lo es Vallejo: un vanguardista solipsista que se parece menos a un contemporáneo que a algún escritor de la tradición con el que dialoga soterradamente. Me pregunto si será posible conjeturar algún poeta o narrador del barroco en ambos escritores.

2) Lespada nos enseña que son los grandes lectores los que van construyendo la imagen de Felisberto, es decir, una imagen en la que se superponen múltiples lecturas críticas, esa afinidad entre la manera de narrar y “la filosofía de la vacilación” de Vaz Ferreira refractaria a las certidumbres; "el humor absurdo" de Mario Benedetti, "el orden de lo insólito" que puede leerse en las fisuras de lo real, observado por Angel Rama; la emergencia de la ficción felisbertiana como el espacio de la verdad según el planteo de Roberto Echavarren; la deliberada refracción de la referencialidad como un modo de escapar a las poéticas de reconocimiento propiciadas por el Realismo, tal como lo describe José Pedro Díaz; esa definición tan acertada de Jules Supervielle cuando declara que el autor de Nadie encendía las lámparas es "un narrador poético entendiendo por él al narrador en el que la poesía, lejos de parcelar y retrasar el relato, a causa de hallazgos añadidos, lo alimenta naturalmente y lo hace vivir”; la emergencia de un yo difuso y timorato de Saúl Yurkievich que abre el camino a la constitución de un sujeto falto, desposeído de bienes en Enrique Pezzoni; sujeto carente de lo cotidiano en Josefina Ludmer o uno que pierde la casa propia y todo se vuelve de algún modo ajeno en Jorge Panesi. En estas lecturas críticas que han sabido simbolizar aspectos ineludibles e insoslayables, que Lespada retoma y, en muchos de los casos, reorienta, podríamos ver dos vertientes: la que enfatiza la constitución de un sujeto atravesado por la falta y la que especula más bien sobre los efectos que una narrativa puede suscitar en la esfera de lo estético, esto es, la liberación que la experiencia estética propicia desde el campo de la 
lectura: reír, vacilar, extrañar, imaginar, acciones todas que los textos felisbertianos inscriben en actitudes vanguardistas, cercanas al humor macedoniano y proclive al teatro del absurdo, donde el sinsentido y la incertidumbre conectan con una filosofía existencialista y una estética cercana al clima onírico del surrealismo, sin adherirse a ningunas de las dos corrientes.

3) Habría que hacerle un lugar especial — entre tantas figuras retóricas que Lespada analiza con fina agudeza - a la prosopopeya o personificación. El uso de esta figura se revela como fundamental en las escrituras tanto poéticas como narrativas ligadas a decisiones vanguadistas. En este aspecto, la relación que puede establecerse es ineludiblemente con el Expresionismo ya que la distorsión del yo se ve proyectado en el mundo de las cosas, que es uno de los núcleos semánticos más fuertes. Lespada da pistas para una lectura distinta del relato felisbertiano: expandir la categoría de lo humano al mundo de las cosas o de los objetos implica cuanto menos una prolongación inquietante. Felisberto —nos plantea Lespada - parece querer romper, quebrar la dimensión antropológica de su arte de narrar, que es lo que no hace nunca Onetti. El mundo material de los objetos bregan por alcanzar un estatuto ontológico, muchas veces en Felisberto borrando la distinción entre el mundo de lo subjetivo y el objetivo, entre la interioridad del yo y el mundo físico en el que necesariamente se instala; una indistinción entre uno y otro que parece, por un lado, establecer líneas de continuidad, tanto como vallas que se interponen entre el sujeto y la realidad. Tanto la fusión como la escisión conciernen por igual al mundo proyectivo de la subjetividad tal como podemos leer, bajo diversas inflexiones, la imagen huérfana y fragmentada del sujeto en Vallejo, la imagen poética en Borges (cuyo ultraísmo está permeado de la poética expresionista, pues recordemos que es precisamente el joven Borges quien tradujo por primera vez a los expresionistas alemanes al español), las descripciones exorbitadas de Roberto Arlt, el teatro grotesco de Discépolo, las deformaciones sutiles de Onetti, para sólo nombrar unos pocos casos relevantes que, junto con la de Felisberto, configuran las narrativas y las poéticas en las que el Expresionismo ha dejado huellas indiscutibles. Sólo que Lespada muestra que la singularidad de Felisberto acerca del uso expresionista de la prosopopeya reside, fundamentalmente, en el devenir humano de la cosas. Hay una antropología de la cosa, a la que se le permite acceder no sólo a la consistencia sino también a la existencia. No es que estamos meramente ante un proceso estético de humanización de las cosas, sino ante las figuraciones animadas de lo inanimado, como si Felisberto indagara en las asociaciones más arbitrarias (toda asociación promovida por el sujeto está necesariamente sujeta a ciertas prerrogativas; la tan mentada asociación libre pareciera no serlo del todo, no al menos en el sentido que los surrealistas creyeron alcanzarlo con el automatismo psíquico). Si una falleba y un gozne podían configurar un matiz sexual en Felisberto, lo que el procedimiento de la asociación pone de manifiesto es la tendencia a la animación, el ardid por el cual se dota de alma a las cosas que, en principio, carecen de ella. Lo que prevalece entonces es un uso figurado y desfigurado como un modo casi autónomo de concebir a las cosas que pueblan el mundo, su entorno cotidiano, su intrincada trama de reificación. Sospechamos que la proposición más consistente de todas las planteadas por Lespada es pensar la posibilidad felisbertiana de expandir la categoría de lo humano al abigarrado mundo de las cosas, precisamente allí donde, según la lectura marxiana del trabajo moderno, la alienación es la transformación del hombre en cosa mientras que el uruguayo realiza el movimiento opuesto: no la cosificación [reificación] del hombre sino el devenir humano de la cosa, volviéndola animada, destituyéndola de la coseidad para inscribirla en lo humano. Esta forma de leer a Felisberto es un desafío crítico porque, más allá de ser consciente de que estamos dentro de las formas simbólicas de las representaciones estéticas, entendemos que son precisamente estas formas las que pueden encender las lámparas para las noches que se avecinan. Felisberto bregaba por una literatura que permita desalienar al hombre contemporáneo que pensamos vigente todavía en nuestra actualidad. 